\title{
Early serodiagnosis of trichinellosis by ELISA using excretory-secretory antigens of Trichinella spiralis adult worms
}

\author{
Ge-Ge Sun, Zhong-Quan Wang ${ }^{*}$, Chun-Ying Liu, Peng Jiang, Ruo-Dan Liu, Hui Wen, Xin Qi, Li Wang and Jing Cui
}

\begin{abstract}
Background: The excretory-secretory (ES) antigens of Trichinella spiralis muscle larvae (ML) are the most commonly used diagnostic antigens for trichinellosis. Their main disadvantage for the detection of anti-Trichinella lgG is false-negative results during the early stage of infection. Additionally, there is an obvious window between clinical symptoms and positive serology.

Methods: ELISA with adult worm (AW) ES antigens was used to detect anti-Trichinella lgG in the sera of experimentally infected mice and patients with trichinellosis. The sensitivity and specificity were compared with ELISAs with AW crude antigens and ML ES antigens.

Results: In mice infected with $100 \mathrm{ML}$, anti-Trichinella lgG were first detected by ELISA with the AW ES antigens, crude antigens and ML ES antigens 8, 12 and 12 days post-infection (dpi), respectively. In mice infected with $500 \mathrm{ML}$, specific antibodies were first detected by ELISA with the three antigen preparations at 10, 8 and 10 dpi, respectively. The sensitivity of the ELISA with the three antigen preparations for the detection of sera from patients with trichinellosis at 35 dpi was $100 \%$. However, when the patients' sera were collected at $19 \mathrm{dpi}$, the sensitivities of the ELISAs with the three antigen preparations were $100 \%$ (20/20), $100 \%(20 / 20)$ and $75 \%(15 / 20)$, respectively $(P<0.05)$. The specificities of the ELISAs with the three antigen preparations were $98.11,95.60$ and $89.31 \%$, respectively $(P<0.05)$.
\end{abstract}

Conclusions: The sensitivity and specificity of the T. spiralis AW ES antigens were superior to those of the AW crude antigens and ML ES antigens. Thus, the AW ES antigens might serve as potential antigens for the early and specific serodiagnosis of trichinellosis.

Keywords: Trichinella spiralis, Trichinellosis, Adult worm, Excretory-secretory (ES) antigens, Serodiagnosis

\section{Background}

Trichinellosis is a serious zoonotic disease caused by the nematode genus Trichinella. Humans acquire the disease by ingesting raw or insufficiently cooked meat of pigs or other animals containing the Trichinella larvae [1]. Human trichinellosis has been documented in 55 countries around the world and is considered to be a neglected tropical disease, especially in developing countries [2, 3]. From 2004 to 2009, 15 outbreaks of human trichinellosis consisting of 1387 cases and 4 deaths were reported in China [4]. Trichinellosis is a major food-borne zoonosis with health, social, and economic impacts in endemic countries [5].

\footnotetext{
* Correspondence: wangzq@zzu.edu.cn; cuij@zzu.edu.cn

Department of Parasitology, Medical College, Zhengzhou University, Zhengzhou, China
}

Following the ingestion of infested meat, Trichinella larvae are released from their capsules to invade the upper small intestine and mature into adult worms (AW). The hallmark of the intestinal phase, which usually lasts 1 week, is a non-specific gastroenteritis, with diarrhoea, abdominal pain, nausea, and/or vomiting. In 2-3 weeks, the fertilized females produce $\sim 1500$ newborn larvae that migrate via the blood and lymphatic systems to invade and encapsulate in the skeletal muscles (muscular or acute phase). The acute phase is associated with an inflammatory and allergic response to muscle invasion by the migrating larvae. Fever, eyelid or facial oedema, myalgia, and eosinophilia are the most prominent manifestations [6, 7].

However, the clinical diagnosis of human trichinellosis is difficult because its clinical manifestations are nonspecific 
$[6,7]$. At present, a definitive diagnosis of human trichinellosis can be made by detecting larvae in a muscle biopsy sample or specific anti-Trichinella IgG antibodies [8], but the parasitological examination of biopsy samples is not sufficiently sensitive to detect Trichinella larvae in light infections and during the early stage of infection. Because T. spiralis muscle larvae (ML) are easily collected from experimentally infected animals, their excretory-secretory (ES) antigens can be prepared by the in vitro cultivation of isolated muscle larvae, resulting in a preparation with high specificity [9]. Thus, an ELISA with the ML ES antigens is the most commonly used serological method for the diagnosis of trichinellosis and is recommended by the International Commission on Trichinellosis (ICT) [10, 11]. The main disadvantage of the detection of anti-Trichinella IgG against ML ES antigens is the occurrence of a high rate of false negative results during the early stage of infection [12]. These false negatives may occur because the majority of $T$. spiralis ML ES antigens are stage-specific; thus, the ML ES antigens are not recognized by antibodies induced by the parasites during the intestinal phase $[13,14]$. Several studies demonstrated that the maximum detection rate of $100 \%$ of anti-Trichinella IgG was not reached until at least 1-3 months after human infection with the parasite [10]. There is an obvious time lag (window period) between the time when patients develop clinical symptoms and positive serology during the acute stage of trichinellosis $[6,15]$. Additionally, the ML ES antigens also have cross-reactivity with the sera of patients with other helminthiases (e.g., paragonimiasis, schistosomiasis, clornorchiasis, cysticercosis, and anisakiasis) [15-17]. Hence, there is an urgent need to develop new specific early diagnostic antigens for acute trichinellosis.

Trichinella spiralis ML develop to AW in the small intestine $31 \mathrm{~h}$ after infection, live in the intestinal mucosa and persist for 10-20 days in mice and rats or 4-6 weeks in humans [18]. During the intestinal stage of trichinellosis, the ES antigens produced by the AW result in early exposure to the immune system and elicit the production of specific anti-Trichinella antibodies by the host. Previous studies showed that AW crude antigens were recognized by infected sera from mice or swine 7 days post-infection (dpi) [19]. However, to the best of our knowledge there has been no report on the serodiagnosis of trichinellosis using T. spiralis AW ES antigens. The aim of this study was to evaluate the potential of $T$. spiralis AW ES antigens for the early serodiagnosis of acute trichinellosis.

\section{Methods}

\section{Ethics statement}

All procedures of animal experiments and the use of the patients' serum samples in this study were approved by the Life Science Ethics Committee of Zhengzhou University (no. 2011-016). Before the investigation, oral informed consent was obtained from all individuals.

\section{Parasites and experimental animals}

The isolate (ISS534) of T. spiralis used in this study was obtained from domestic pigs in Nanyang, Henan Province, China. The reference Trichinella isolates used in this study were $T$. nativa (T2, ISS10), $T$. britovi (T3, ISS100), $T$. pseudospiralis (T4, ISS13) and T. nelsoni (T7, ISS29); these isolates were obtained from the International Trichinella Reference Centre (ITRC; Rome, Italy). The Trichinella isolates were maintained by serial passage in BALB/c mice every 6-8 months in our laboratory. Specific pathogen-free (SPF) female BALB/c mice aged 6 weeks were purchased from the Experimental Animal Centre of Henan Province.

\section{Serum samples}

T. spiralis was used to infect the BALB/c mice. Twenty mice were randomly divided into two groups (ten mice per group): mice infected with $500 \mathrm{ML}$ and mice infected with $100 \mathrm{ML}$. Approximately $100 \mu \mathrm{l}$ of tail blood was collected from the infected mice on alternate days from 2-28 dpi to isolate sera [12]. Serum samples from normal mice were used as the negative control.

Sera were obtained from BALB/c mice infected with 300 ML of T. spiralis, T. nativa, T. britovi, T. pseudospiralis and T. nelsoni $42 \mathrm{dpi}$. Serum samples of mice infected with three spargana of Spirometra mansoni were collected $30 \mathrm{dpi}$ in our department. Serum samples of mice infected with Toxoplasma gondii, Schistosoma japanicum and Angiostrongylus cantonensis were gifted by Prof. GR Yin (Shanxi Medical University), Dr. JH Lei (Tongji Medical College of Huazhong University of Science and Technology), and Prof. ZY Lv (Department of Parasitology, Zhongshan School of Medicine, Sun Yat-Sen University), respectively. All of the serum samples were stored at $-80{ }^{\circ} \mathrm{C}$ prior to use.

Forty-two serum samples from patients with trichinellosis were used to identify the sensitivity of the $T$. spiralis AW ES antigens. These serum samples were collected from the patients during two outbreaks with trichinellosis that occurred in the Yunnan province of southwestern China in 2003 and 2013 [20, 21]. These patients with trichinellosis presented with a clinical suspicion of trichinellosis. The diagnosis of trichinellosis was confirmed for all of these patients by the presence of a high fever associated with periorbital or facial oedema, myalgia, a high level of eosinophilia, and a history of ingestion of raw or undercooked meat. All of these patients had positive ELISA or IIF results for trichinellosis, and two patients had a Trichinella-positive muscle biopsy. Out of 42 patients with trichinellosis, 22 serum samples were collected 35 dpi and 20 were collected 19 dpi. 
Sera used to assess cross-reactivity were selected from 109 patients with other parasitic diseases confirmed by parasitological examination of faeces, histopathological examination of biopsy samples or positive specific serological test results: schistosomiasis (36 patients with Schistosoma japonicum infection), paragonimiasis (20 patients with Paragonimus skrjabini infection), clonorchiasis (7 patients with Clonorchis sinensis), cystic echinococcosis (21 patients), Taenia solium cysticercosis (18 patients), and Spirometra erinaceieuropaei sparganosis (7 patients). These patients were diagnosed and serum samples were collected in our department $[22,23]$. Serum samples from 50 presumably healthy persons who tested negative for the above-mentioned parasitic diseases were also included in the study. All of the serum samples were stored at $-80{ }^{\circ} \mathrm{C}$ prior to use.

\section{Collection of worms and preparation of ES antigens}

One hundred mice were orally infected with $5000 \mathrm{ML}$ of T. spiralis and euthanized $3 \mathrm{dpi}$. The small intestine was collected, cut along its entire length, and washed in pre-warmed PBS. Then, the small intestine was cut into pieces and incubated in PBS at $37{ }^{\circ} \mathrm{C}$ for $1.5 \mathrm{~h}$ on a $300 \mu \mathrm{m}$ sieve. The released AW were separated from the intestinal debris by filtration through a $200 \mu \mathrm{m}$ sieve and differential sedimentation for $30 \mathrm{~min}$. After several washes in PBS supplemented with $100 \mathrm{U}$ penicillin/ml and $100 \mu \mathrm{g}$ streptomycin $/ \mathrm{ml}$, the worms were centrifuged at $600 \times \mathrm{g}$ for $10 \mathrm{~min}$ and collected $[19,24,25]$. The average number of AW recovered from the infected mice was approximately 1000 worms per mouse.

AW ES antigens were prepared as previously described $[9,26]$. Briefly, after thorough washing in sterile saline and serum-free RPMI-1640 medium supplemented with 100 $\mathrm{U}$ penicillin/ml and $100 \mu \mathrm{g}$ streptomycin $/ \mathrm{ml}$, the AW were incubated in the same medium at a density of 2000 worms $/ \mathrm{ml}$ at $37{ }^{\circ} \mathrm{C}$ in $5 \% \mathrm{CO}_{2}$ for $18 \mathrm{~h}$. After incubation, the media containing the ES proteins were poured into $50-\mathrm{ml}$ conical tubes, and the worms were allowed to settle for $20 \mathrm{~min}$. The supernatant containing the ES products was filtered through a $0.2 \mu \mathrm{m}$ membrane. The ES products were dialyzed and then lyophilized by vacuum concentration and freeze-drying (Heto-Holten A/S, Denmark). The protein concentration of the ES antigens of the adult worms was determined by the Bradford assay [27].

$T$. spiralis ML were recovered from the infected mice 42 dpi by artificial digestion [28, 29]. The ML ES antigens were prepared as described above.

The crude (somatic) antigens of $T$. spiralis AW were prepared as previously described [30, 31]. Briefly, adults were resuspended in deionized water. The suspension was subjected to 5 freeze-thaw cycles. The worms were homogenized on ice in a glass tissue grinder. Then, the larval fragments were further homogenized with ultrasonication
(99 3-s cycles, $100 \mathrm{~W}, 0{ }^{\circ} \mathrm{C}$ ). The supernatant was collected after centrifugation at $15,000 \times \mathrm{g}$ for $1 \mathrm{~h}$ at $4{ }^{\circ} \mathrm{C}$. The protein concentration of the AW crude antigens was determined by the Bradford assay [27].

\section{Enzyme-linked immunosorbent assay}

The optional dilutions of various reagents were determined using checkerboard titration. ELISA was performed as previously described [15, 32]. Briefly, 96-well ELISA plates (Corning, USA) were coated with AW ES antigens $(2.0 \mu \mathrm{g} /$ $\mathrm{ml}), \mathrm{ML}$ ES antigens $(2.5 \mu \mathrm{g} / \mathrm{ml})$ or AW crude antigens $(1.5 \mu \mathrm{g} / \mathrm{ml})$ in $100 \mu \mathrm{l}$ of bicarbonate buffer ( $\mathrm{pH} 9.6)$ overnight at $4{ }^{\circ} \mathrm{C}$. After blocking with PBS-0.1\% Tween 20 (PBST) containing $5 \%$ skimmed milk at $37^{\circ} \mathrm{C}$ for $2 \mathrm{~h}$, the following reagents were sequentially added and incubated at $37^{\circ} \mathrm{C}$ for $1 \mathrm{~h}$ : (1) human or mouse sera diluted 1:200 or 1:100, respectively, in PBST, and (2) HRP-conjugated antihuman or anti-mouse IgG (Sigma, USA) diluted 1:5000. The reactions were detected by the addition of the substrate o-phenylenediamine dihydrochloride (OPD; Sigma, USA) plus $\mathrm{H}_{2} \mathrm{O}_{2}$ and stopped with $50 \mu \mathrm{l} /$ well of $2 \mathrm{M} \mathrm{H}_{2} \mathrm{SO}_{4}$. Optical density (OD) values at $490 \mathrm{~nm}$ were measured with a microplate reader (TECAN, Austria). All samples were run in duplicate.

The cut-off value of the ELISA was evaluated for the three antigen preparations based on a 2.1-fold increase over the average OD value of the negative samples. Ratios $<2.1$ of the samples to be tested/negative sample (OD values of the samples to be tested divided by OD of the negative, $\mathrm{S} / \mathrm{N}<2.1$ ) were regarded as negative, whereas $\mathrm{S} / \mathrm{N} \geq 2.1$ was regarded as positive [15, 23, 33]. A test was considered valid when: (1) the OD values of the negative controls were higher than the OD values of the blank controls; and (2) the OD values of the negative controls were lower than the cut-off values. The sensitivity and specificity of the ELISA were assessed according to the following formulas: Sensitivity $=$ no. of true positives/(no. of true positives + no. of false negatives $) \times 100$ and Specificity $=$ no. of true negatives/(no. of false positives + no. of true negatives $) \times 100[34]$.

\section{Statistical analysis}

All statistical analyses were performed with SPSS for Windows, version 17.0 (SPSS Inc., Chicago, IL, USA). The sensitivity and specificity of the AW ES, crude antigens and ML ES antigens were compared with the Chi-square test. Repeated-measures analysis of variance was used to determine the difference between antibody levels at various time points post-infection and with different infecting doses. $P<0.05$ was considered statistically significant. 
Table 1 Detection of serum anti-Trichinella lgG in mice infected with Trichinella spiralis and other parasites by ELISA with the three T. spiralis antigen preparations

\begin{tabular}{|c|c|c|c|c|c|c|c|}
\hline \multirow{2}{*}{$\begin{array}{l}\text { Sera of mice } \\
\text { infected with }\end{array}$} & \multirow{2}{*}{$\begin{array}{l}\text { No. of serum } \\
\text { samples }\end{array}$} & \multicolumn{2}{|c|}{ ELISA with AW ES antigens } & \multicolumn{2}{|c|}{ ELISA with AW crude antigens } & \multicolumn{2}{|c|}{ ELISA with ML ES antigens } \\
\hline & & $\begin{array}{l}\text { OD value } \\
(\bar{X} \pm S)\end{array}$ & $\begin{array}{l}\text { No. of positive serum } \\
\text { samples (\%) }\end{array}$ & $\begin{array}{l}\text { OD value } \\
(\bar{X} \pm S)\end{array}$ & $\begin{array}{l}\text { No. of positive serum } \\
\text { samples (\%) }\end{array}$ & $\begin{array}{l}\mathrm{OD} \text { value } \\
(\overline{\mathrm{X}} \pm S)\end{array}$ & $\begin{array}{l}\text { No. of positive serum } \\
\text { samples (\%) }\end{array}$ \\
\hline T. spiralis & 35 & $0.60 \pm 0.11$ & $35(100)$ & $0.43 \pm 0.09$ & $35(100)$ & $0.58 \pm 0.13$ & $35(100)$ \\
\hline A. cantonensis & 12 & $0.06 \pm 0.01$ & $0(0)$ & $0.05 \pm 0.01$ & $0(0)$ & $0.03 \pm 0.01$ & $0(0)$ \\
\hline S. mansoni & 26 & $0.11 \pm 0.04$ & $0(0)$ & $0.12 \pm 0.04$ & $0(0)$ & $0.15 \pm 0.03$ & $0(0)$ \\
\hline S. japonicum & 16 & $0.15 \pm 0.05$ & $0(0)$ & $0.12 \pm 0.03$ & $0(0)$ & $0.15 \pm 0.06$ & $0(0)$ \\
\hline T. gondii & 6 & $0.10 \pm 0.04$ & $0(0)$ & $0.11 \pm 0.05$ & $0(0)$ & $0.14 \pm 0.01$ & $0(0)$ \\
\hline Normal mice & 46 & $0.09 \pm 0.02$ & $0(0)$ & $0.12 \pm 0.02$ & $0(0)$ & $0.09 \pm 0.02$ & $0(0)$ \\
\hline
\end{tabular}

\section{Results}

\section{The ELISA cut-off values}

The cut-off values of the ELISA with the AW ES antigens, crude antigens and ML ES antigens for the detection of experimentally infected mice were $0.19,0.23$ and 0.20 , respectively. The cut-off values of the ELISA with the above three antigen preparations for the detection of patients with trichinellosis were $0.41,0.47$ and 0.45 , respectively.

\section{Detection of anti-Trichinella IgG in mice infected with Trichinella and other parasites}

The levels of anti-Trichinella IgG in the serum samples of mice infected with $T$. spiralis and other parasites were determined; the results are shown in Table 1. The sensitivity of the ELISA with the AW ES antigens, crude antigens and ML ES antigens for the detection of anti-Trichinella IgG in the sera of mice infected with $300 \mathrm{~T}$. spiralis ML collected at $42 \mathrm{dpi}$ was $100.00 \%(35 / 35)$. No cross-reactivity of the ELISAs with the three antigen preparations was observed with the sera of mice infected with Angiostrongylus cantonensis, Spirometra mansoni, Schistosoma japonicum, and T. gondii and normal mice.

The levels of anti-Trichinella IgG in mice infected with other Trichinella species were assessed by ELISA; the results are shown in Table 2. The detection rates of anti-Trichinella IgG by ELISA with the AW and ML ES antigens were $100 \%$ in mice infected with T. nativa, $T$. britovi and T. nelsoni. However, the antibody detection rate $(90.91 \%)$ of mice infected with $T$. pseudospiralis by ELISA with the ML ES antigens was $9.09 \%$ higher than the ELISA with the AW ES antigens $\left(\chi^{2}=29.455, P<\right.$ $0.05)$. When the sera of mice infected with $T$. nativa, $T$. britovi, T. nelson or T. pseudospiralis were assessed by ELISA with the AW crude antigens, the antibody detection rates were significantly lower compared to the ELISA with the ML ES antigens $\left(\chi_{\mathrm{T} 2}^{2}=29.939, \chi_{\mathrm{T} 3}^{2}=17.368, \chi_{\mathrm{T} 4}^{2}=\right.$ 36.667 , and $\chi_{\mathrm{T} 7}^{2}=14.545$, respectively, $P<0.05$.

\section{Serum anti-Trichinella lgG dynamics in mice experimentally} infected with different numbers of parasites

The levels of anti-Trichinella IgG in the sera from the 2 groups of infected mice at different time points after infection were determined by ELISA with the three antigens preparations (Fig. 1). The results showed that the serum anti-Trichinella IgG levels in mice infected with 100 and 500 larvae began to increase rapidly $8 \mathrm{dpi}$ and continued to elevate throughout the experimental period. There were significant differences in the anti-Trichinella IgG levels at different time points post-infection in the 2 groups of infected mice $\left(F_{\mathrm{WA} \text { ES }}=408.307, \mathrm{~F}_{\mathrm{AW}}\right.$ crude $=204.921$, and $\left.\mathrm{F}_{\mathrm{ML}} \mathrm{ES}=165.990, P<0.05\right)$. When the AW ES antigens were used, the anti-Trichinella IgG levels in the mice infected with 100 larvae were higher than the mice infected with 500 larvae $(F=68.023, P<0.05)$. However, when the AW crude antigens and ML ES antigens were used, the anti-Trichinella IgG levels in the mice infected with 500 larvae were obviously higher compared to the mice infected with 100 larvae $\left(\mathrm{F}_{\mathrm{AW} \text { crude }}=38.118\right.$ and $\mathrm{F}_{\mathrm{ML} \text { ES }}=5.999, P<$ 0.05). In the mice infected with $100 \mathrm{ML}$, anti-Trichinella IgG was first detected by ELISA with the AW ES antigens,

Table 2 Detection of serum anti-Trichinella lgG in mice infected with other Trichinella species by ELISA with the three T. spiralis antigen preparations

\begin{tabular}{|c|c|c|c|c|c|c|c|}
\hline \multirow{2}{*}{$\begin{array}{l}\text { Sera of mice } \\
\text { infected with }\end{array}$} & \multirow{2}{*}{$\begin{array}{l}\text { No. of serum } \\
\text { samples }\end{array}$} & \multicolumn{2}{|c|}{ ELISA with AW ES antigens } & \multicolumn{2}{|c|}{ ELISA with AW crude antigens } & \multicolumn{2}{|c|}{ ELISA with ML ES antigens } \\
\hline & & $\begin{array}{l}\text { OD value } \\
(\bar{X} \pm S)\end{array}$ & $\begin{array}{l}\text { No. of positive serum } \\
\text { samples (\%) }\end{array}$ & $\begin{array}{l}\text { OD value } \\
(\bar{X} \pm S)\end{array}$ & $\begin{array}{l}\text { No. of positive serum } \\
\text { samples (\%) }\end{array}$ & $\begin{array}{l}\text { OD value } \\
(\bar{X} \pm S)\end{array}$ & $\begin{array}{l}\text { No. of positive serum } \\
\text { samples (\%) }\end{array}$ \\
\hline T. nativa & 26 & $0.34 \pm 0.12$ & $26(100)$ & $0.18 \pm 0.08$ & $7(26.92)$ & $0.71 \pm 0.13$ & $26(100)$ \\
\hline T. britovi & 15 & $0.40 \pm 0.12$ & $15(100)$ & $0.20 \pm 0.12$ & $4(26.67)$ & $0.79 \pm 0.08$ & $15(100)$ \\
\hline T. pseudospiralis & 22 & $0.06 \pm 0.07$ & $2(9.09)$ & $0.06 \pm 0.02$ & $0(0)$ & $0.52 \pm 0.21$ & $20(90.91)$ \\
\hline T. nelsoni & 16 & $0.31 \pm 0.09$ & $16(100)$ & $0.20 \pm 0.14$ & $6(37.50)$ & $0.76 \pm 0.08$ & $16(100)$ \\
\hline
\end{tabular}



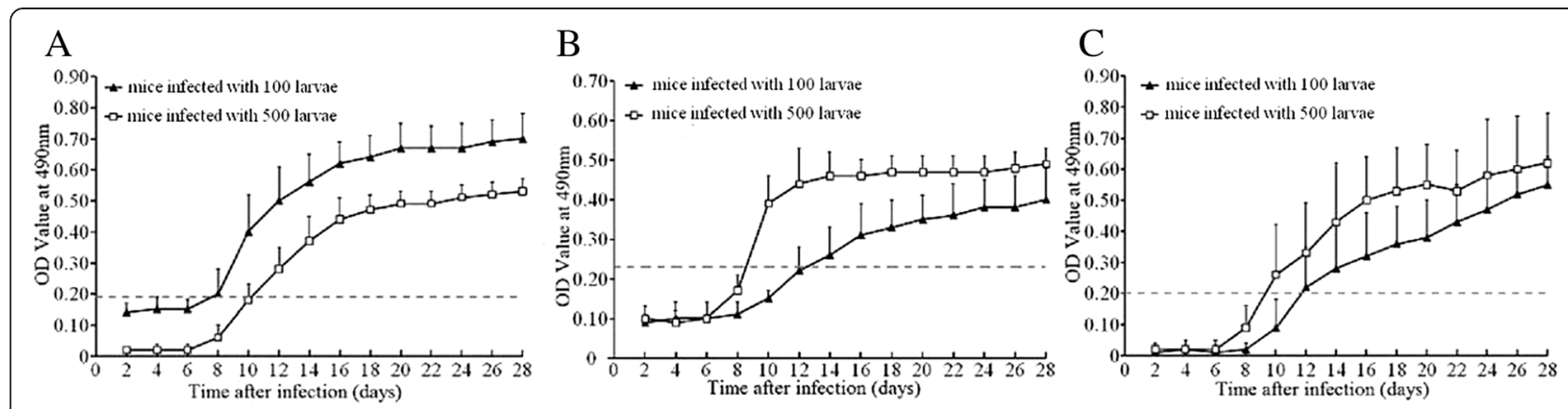

Fig. 1 Kinetics of anti-Trichinella lgG in the sera of mice infected with 500 and 100 muscle larvae. Anti-Trichinella lgG was detected by ELISA with adult worm ES antigens (a), adult worm crude antigens (b) and muscle larval ES antigens (c). The cut-off value is represented by the dotted line

crude antigens and ML ES antigens 8, 12 and 12 dpi with detection rates of 50,40 and $40 \%$, respectively; the antibody positivity rates reached $100 \%$ on 10,18 and $24 \mathrm{dpi}$, respectively (Figs. $2 \mathrm{a}$ and 3 ). In the mice infected with 500 ML, anti-Trichinella IgG was first detected by ELISA with the three antigens on 10, 8 and $10 \mathrm{dpi}$ with detection rates of 60,20 and $50 \%$, respectively; the antibody positivity rates reached $100 \%$ on 12, 10 and 16 dpi, respectively (Fig. 2b).

\section{Detection of anti-Trichinella IgG in serum samples of patients with trichinellosis and other parasitoses}

The sensitivity of ELISA with the AW ES antigens, crude antigens and ML ES antigens for the detection of antiTrichinella IgG in the sera of patients with trichinellosis was $100 \%$ on 35 dpi (22/22) (Table 3). However, when the patients' sera were collected $19 \mathrm{dpi}$, the sensitivity of the ELISAs with the three antigens was $100 \%$ (20/20), $100 \%$ $(20 / 20)$ and $75 \%(15 / 20)$, respectively $\left(\chi^{2}=10.909, P<\right.$ $0.05)$. The specificity of the ELISAs with the three antigens was $98.11 \%$ (156/159), $95.60 \%(152 / 159)$ and $89.31 \%$ $(142 / 159)$, respectively $\left(X^{2}=12.249, P<0.05\right)$, when performed with the sera of patients with other parasitic diseases and healthy persons. No cross-reactions of the ELISA with the AW ES antigens and crude antigens were observed with the sera of patients with schistosomiasis, clonorchiosis, echinococcosis, and sparganosis, and healthy persons. However, the cross-reactivity ( $25 \%$ ) of the ELISA with the AW crude antigens with the sera of patients with paragonimiasis was higher than $10 \%$ with the AW ES antigens, although the difference was not statistically significant $\left(X^{2}=1.558, P>0.05\right)$.

\section{Discussion}

In the present study, the AW ES antigens of $T$. spiralis were used as diagnostic antigens for the detection of antiTrichinella IgG in the sera of experimentally infected mice. The sensitivity and specificity of the ELISA with the AW ES antigens were $100 \%(35 / 35)$ and $100 \%(106 / 106)$ in the infected mice, respectively. Moreover, there was no significant difference in the antibody detection rates in the sera of mice infected with $T$. nativa, $T$. britovi, and T. nelsoni by ELISA with the AW ES antigens and ML ES antigens $(P>0.05)$. The results suggested that there were common AW ES antigens among the encapsulated Trichinella species (i.e., T. spiralis, T. nativa, T. britovi, and T. nelsoni), but not in the non-encapsulated Trichinella species (T. pseudospiralis) [35, 36]. Moreover, most of the epitopes of the AW ES antigens recognized by sera from infected mice were common to the encapsulated Trichinella species [37]. Our results indicated that the AW ES antigens of $T$. spiralis could also be used for the serodiagnosis of trichinellosis caused by other encapsulated Trichinella species.
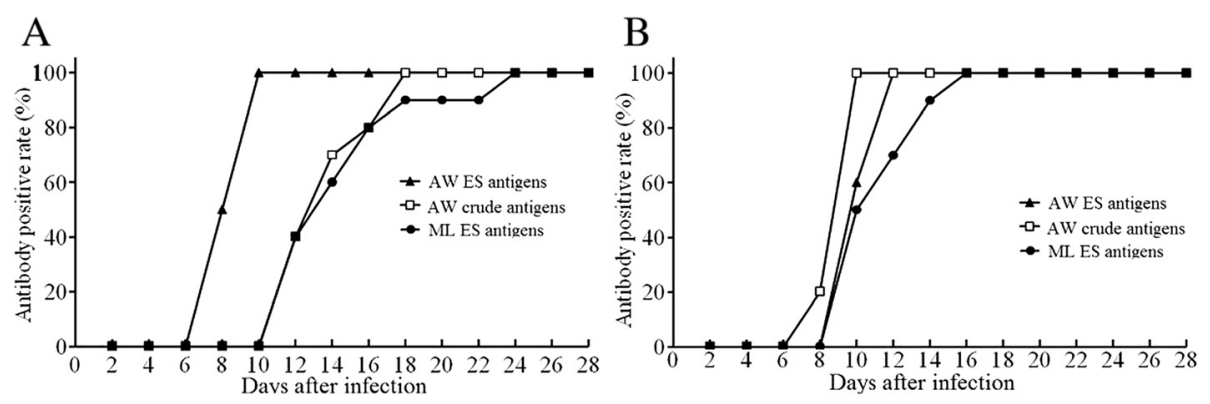

Fig. 2 Comparison of the detection rate of anti-Trichinella lgG in the sera of mice infected with different numbers of larvae by ELISA with the three antigen preparations. a mice infected with 100 larvae. b mice infected with 500 larvae 


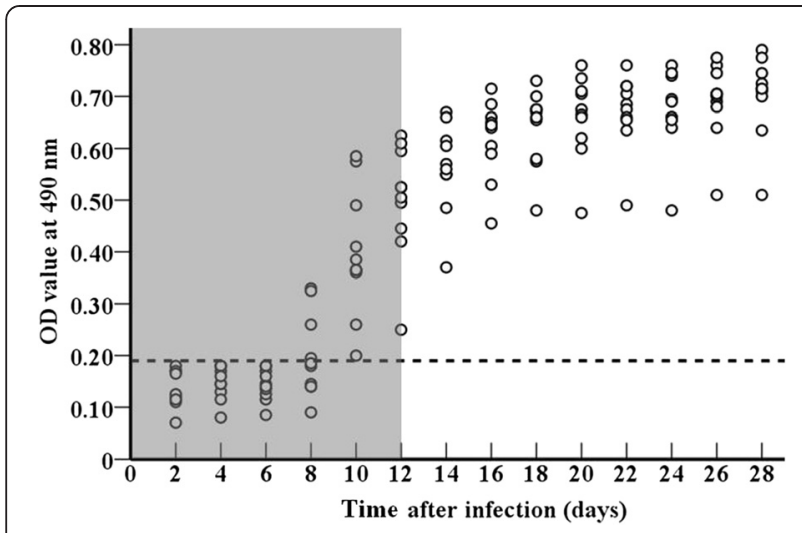

Fig. 3 Optical density values from the ELISA with adult worm ES antigens of mice infected with $100 \mathrm{~T}$. spiralis muscle larvae. The cut-off value is represented by the dotted line. The window where the detection of anti-Trichinella lgG is not possible by ELISA with the muscle larval ES antigens is presented in grey

Our ELISA results showed that the antigenic epitopes of the AW ES antigens were recognized by sera from infected mice 8-12 dpi, suggesting that the AW ES antigens might be secreted into the peripheral blood circulation of the host during the intestinal stage of Trichinella infection and induce an early antibody response that continues into the muscle larval stage [15]. Importantly, the anti-Trichinella IgG in $50 \%$ of the mice infected with 100 larvae was detected by ELISA with the AW ES antigens as soon as $8 \mathrm{dpi}$, whereas the ELISA with the ML ES antigens did not permit detection of the infected mice before $12 \mathrm{dpi}$. In contrast, anti-Trichinella IgG in the mice infected with 500 larvae was first detected by ELISA with the AW ES antigens on $10 \mathrm{dpi}$. The mechanism underlying the earlier detection of anti-Trichinella IgG by the AW ES antigens in mice infected with 100 larvae compared to mice infected with 500 larvae is unclear, but may be due to the suppression of the host's immune response to the AW ES antigens by the higher infecting doses during the early stage of Trichinella infection $[38,39]$. Other studies showed that the recombinant proteins from the early adult worms $20 \mathrm{~h}$ post-infection were recognized by Western blotting as soon as 15-20 dpi in sera from pigs experimentally infected with 20,000 T. spiralis muscle larvae [40]. These results suggested that the AW ES antigens were more sensitive than the recombinant AW antigens for the serodiagnosis of trichinellosis. Thus, the AW ES antigens of T. spiralis exhibit potential for the early diagnosis of trichinellosis.

The sensitivity of the ELISAs with the AW ES antigens and ML ES antigens towards early patient serum samples collected on 19 dpi were 100 and $75 \%(P<0.05)$, respectively, suggesting that the AW ES antigens had early serodiagnostic value for human trichinellosis.

Cross-reactive antigens from different species of helminths have been known since the initial studies of Capron et al. [41]. Previous studies showed that the ELISA with the ML crude antigens exhibited obvious cross-reactivity with the sera of patients infected with other helminths [42]. Although the use of ML ES antigens could increase the sensitivity of the ELISA, $39.2 \%$ of the false-positive results were observed with sera from patients with other parasitic diseases (cysticercosis, hydatidosis, schistosomiasis, fascioliasis, strongyloidosis, toxocariasis, anisakiasis or filariasis) [17]. When synthetic tyvelose antigens of $T$. spiralis ML were used for the serodiagnosis of trichinellosis, cross-reactivity occurred with cases of anisakiasis [16]. Recently, recombinant antigens of T. spiralis ML have been developed in some laboratories; however, the recombinant Ts 21 or Ts 43 antigens still had a high occurrence of cross-reactivity with the sera of patients with

Table 3 Detection of anti-Trichinella lgG in serum samples of patients with trichinellosis and other parasitoses by ELISA with the three T. spiralis antigen preparations

\begin{tabular}{|c|c|c|c|c|c|c|c|}
\hline \multirow[t]{2}{*}{ Sera of patients with } & \multirow{2}{*}{$\begin{array}{l}\text { No. of serum } \\
\text { samples }\end{array}$} & \multicolumn{2}{|c|}{ ELISA with AW ES antigens } & \multicolumn{2}{|c|}{ ELISA with AW soluble antigens } & \multicolumn{2}{|c|}{ ELISA with ML ES antigens } \\
\hline & & $\begin{array}{l}\text { OD value } \\
(\bar{X} \pm S)\end{array}$ & $\begin{array}{l}\text { No. of positive serum } \\
\text { samples (\%) }\end{array}$ & $\begin{array}{l}\text { OD value } \\
(\bar{X} \pm S)\end{array}$ & $\begin{array}{l}\text { No. of positive Serum } \\
\text { samples (\%) }\end{array}$ & $\begin{array}{l}\text { OD value } \\
(\bar{X} \pm S)\end{array}$ & $\begin{array}{l}\text { No. of positive serum } \\
\text { samples (\%) }\end{array}$ \\
\hline Later trichinellosis $^{\mathrm{a}}$ & 22 & $0.52 \pm 0.10$ & $22(100)$ & $0.54 \pm 0.05$ & $22(100)$ & $0.68 \pm 0.04$ & $22(100)$ \\
\hline Early trichinellosis ${ }^{\mathrm{b}}$ & 20 & $0.56 \pm 0.12$ & $20(100)$ & $0.62 \pm 0.08$ & $20(100)$ & $0.53 \pm 0.10$ & $15(75.00)$ \\
\hline Schistosomiasis & 36 & $0.25 \pm 0.06$ & $0(0)$ & $0.30 \pm 0.07$ & $0(0)$ & $0.33 \pm 0.10$ & $4(20.00)$ \\
\hline Paragonimiosis & 20 & $0.29 \pm 0.11$ & $2(10.00)$ & $0.40 \pm 0.14$ & $5(25.00)$ & $0.26 \pm 0.14$ & $1(5.00)$ \\
\hline Clonorchiosis & 7 & $0.21 \pm 0.04$ & $0(0)$ & $0.22 \pm 0.05$ & $0(0)$ & $0.30 \pm 0.11$ & $1(14.29)$ \\
\hline Cysticercosis & 18 & $0.28 \pm 0.10$ & $1(5.56)$ & $0.29 \pm 0.12$ & $2(11.00)$ & $0.38 \pm 0.12$ & $5(25.00)$ \\
\hline Echinococcosis & 21 & $0.27 \pm 0.07$ & $0(0)$ & $0.28 \pm 0.07$ & $0(0)$ & $0.35 \pm 0.14$ & $5(25.00)$ \\
\hline Sparganosis & 7 & $0.26 \pm 0.04$ & $0(0)$ & $0.34 \pm 0.04$ & $0(0)$ & $0.27 \pm 0.10$ & $1(12.5)$ \\
\hline Healthy persons & 50 & $0.19 \pm 0.03$ & $0(0)$ & $0.23 \pm 0.04$ & $0(0)$ & $0.21 \pm 0.08$ & $0(0)$ \\
\hline
\end{tabular}

Later trichinellosis $^{\mathrm{a}}$ : The sera of later patients with trichinellosis were collected 35 days post-infection Early trichinellosis ${ }^{b}$ : The sera of patients with early-stage trichinellosis were collected 19 days post-infection 
schistosomiasis, paragonimiasis, clonorchiasis, echinococcosis or cysticercosis $[43,44]$.

Western blotting of crude or ES antigens of $T$. spiralis ML is the serological method for the confirmatory test for trichinellosis recommended by the ICT. When specific IgG antibodies against the ML antigen components (40$70 \mathrm{kDa}$ ) are detected, the diagnosis of Trichinella infection is confirmed [10]. Western blotting with the ML crude or ES antigens is mainly used to confirm ELISA-positive sera from animals and humans. The sensitivity and specificity of this technique range from 96 to $99 \%$ and from 95.6 to $99.6 \%$, respectively $[45,46]$. Hence, Western blotting has been widely applied to the serodiagnosis and seroepidemiological investigation of Trichinella infection in humans and animals [47-50]. However, the 40-70 kDa protein bands of the T. spiralis ML also exhibited cross-reactivity with the sera of patients with other helminthiases $[17,51]$. Moreover, shared antigens have been identified for $T$. spiralis ML and several other parasitic worms (Trichuris spp., Fasciola hepatica, Schistosoma mansoni, Schistosoma japonicum, Paragonimus westermani and Clornorcis sinensis) [52-55]. Anti-gp50 monoclonal antibodies against schistosomes and anti-gp50-positive sera from patients with schistosomiasis cross-reacted with the hypodermis and stichocytes of the T. spiralis ML [56]. These results demonstrated that different kinds of antigens from the $T$. spiralis ML had partial cross-reactivity with the sera of patients with other helminthiases. Hence, new sources of diagnostic antigens from other stages of $T$. spiralis should be developed to improve the sensitivity and specificity of the serodiagnosis of trichinellosis.

Our results showed that the specificity of the T. spiralis AW ES antigens was significantly higher than the ML ES antigens. No cross-reactions of the AW ES antigens were observed with the sera of patients with schistosomiasis, clonorchiosis, echinococcosis, or sparganosis or healthy persons. The AW ES antigens were sensitive and specific for the detection of anti-Trichinella IgG in serum samples of patients in the early stage of trichinellosis. The application of AW ES antigens for the serodiagnosis of trichinellosis could remarkably shorten the window when the detection of anti-Trichinella IgG is not possible by the ELISA with ML ES antigens. The AW ES antigens are a good alternative to the ML ES antigens and should be considered as a potential specific diagnostic antigen preparation for early trichinellosis.

However, cross-reactivity of the ELISA with the AW ES antigens was observed with $5.56 \%(1 / 18)$ of patients with cysticercosis and $10 \%(2 / 20)$ of patients with paragonimiosis. Hence, a large-scale validation of the specificity of the AW ES antigens needs to be performed with the sera of the patients with other helminthiases. Moreover, the Trichinella-specific protein bands in the AW ES antigens should be identified and validated by Western blotting, and specific recombinant AW antigens should be developed in the future.

\section{Conclusions}

This study demonstrated that the AW ES antigens of $T$. spiralis were sensitive and specific for the early diagnosis of trichinellosis. These antigens provided a new source of diagnostic antigens and might serve as potential antigens for the early and specific serodiagnosis of trichinellosis. However, these results need to be further evaluated with a large-scale trial using the sera of patients with trichinellosis and other helminthiases.

\section{Competing interests}

The authors declare that they have no competing interests.

\section{Authors' contributions}

ZQW and JC conceived and designed the experiments. GGS, CYL, PJ, RDL, HW, QX, and LW performed some of the experiments. GGS, ZQW, and JC drafted and revised the manuscript. All authors read and approved the final version of the manuscript.

\section{Acknowledgements}

This work was supported by the National Natural Science Foundation of China (no. 81572024 and 81471981).

Received: 1 July 2015 Accepted: 16 September 2015

Published online: 23 September 2015

\section{References}

1. Cui J, Jiang P, Liu LN, Wang ZQ. Survey of Trichinella infections in domestic pigs from northern and eastern Henan. China Vet Parasitol. 2013;194(2-4):133-5.

2. Pozio E. World distribution of Trichinella spp. infections in animals and humans. Vet Parasitol. 2007;149(1-2):3-21.

3. Bruschi F. Trichinellosis in developing countries: is it neglected? J Infect Dev Ctries. 2012;6(3):216-22.

4. Cui J, Wang ZQ, Xu BL. The epidemiology of human trichinellosis in China during 2004-2009. Acta Trop. 2011;118(1):1-5.

5. Murrell KD, Pozio E. Worldwide occurrence and impact of human trichinellosis, 1986-2009. Emerg Infect Dis. 2011;17(12):2194-202.

6. Wang ZQ, Cui J, Wu F, Mao FR, Jin XX. Epidemiological, clinical and serological studies on trichinellosis in Henan Province. China Acta Trop. 1998;71(3):255-68.

7. Dupouy-Camet J, Kociecka W, Bruschi F, Bolas-Fernandez F, Pozio E. Opinion on the diagnosis and treatment of human trichinellosis. Expert Opin Pharmacother. 2002;3(8):1117-30.

8. Dupuy-Camet J, Bruschi F. Management and diagnosis of human trichinellosis. In: Dupouy-Camet J, Murrell KD, editors. FAO/WHO/OIE guidelines for the surveillance, management, prevention and control of trichinellosis. Paris, 1st ed. FAO/WHO/OIE 2007:37-68.

9. Gamble HR, Rapic D, Marinculic A, Murrell KD. Evaluation of excretory-secretory antigens for the serodiagnosis of swine trichinellosis. Vet Parasitol. 1988;30(2):131-7.

10. Gamble HR, Pozio E, Bruschi F, Nockler K, Kapel CM, Gajadhar AA. International Commission on Trichinellosis: recommendations on the use of serological tests for the detection of Trichinella infection in animals and man. Parasite. 2004;11:3-13.

11. Gottstein B, Pozio E, Nockler K. Epidemiology, diagnosis, treatment, and control of trichinellosis. Clin Microbiol Rev. 2009;22:127-45.

12. Liu LN, Jing FJ, Cui J, Fu GY, Wang ZQ. Detection of circulating antigen in serum of mice infected with Trichinella spiralis by an IgY-lgM mAb sandwich ELISA. Exp Parasitol. 2013;133(2):150-5.

13. Ortega-Pierres MG, Yepez-Mulia L, Homan W, Gamble HR, Lim PL, Takahashi Y, et al. Workshop on a detailed characterization of Trichinella spiralis antigens: a platform for future studies on antigens and antibodies to this parasite. Parasite Immunol. 1996;18(6):273-84. 
14. Tang B, Liu M, Wang L, Yu S, Shi H, Boireau P, et al. Characterisation of a high-frequency gene encoding a strongly antigenic cystatin-like protein from Trichinella spiralis at its early invasion stage. Parasit Vectors. 2015;8:78.

15. Cui J, Wang L, Sun GG, Liu LN, Zhang SB, Liu RD, et al. Characterization of a Trichinella spiralis $31 \mathrm{kDa}$ protein and its potential application for the serodiagnosis of trichinellosis. Acta Trop. 2015;142:57-63.

16. Dea-Ayuela MA, Romaris F, Ubeira FM, Rama-Iniguez S, Martinez-Fernandez $A R$, Bolas F. Possible presence of common tyvelose-containing glycans in Trichinella L1 larvae and embryonated eggs of several nematodes. Parasite. 2001;8:S120-2

17. Yera H, Andiva S, Perret C, Limonne D, Boireau P, Dupouy-Camet J. Development and evaluation of a Western blot kit for diagnosis of human trichinellosis. Clin Diagn Lab Immunol. 2003;10(5):793-6.

18. Campbell WC. Trichinella and Trichinosis. New York: Plenum Press; 1983:75.

19. Yang J, Pan W, Sun X, Zhao X, Yuan G, Sun Q, et al. Immunoproteomic profile of Trichinella spiralis adult worm proteins recognized by early infection sera. Parasit Vectors. 2015:8:20.

20. Wang ZQ, Cui J, Xu BL. The epidemiology of human trichinellosis in China during 2000-2003. Acta Trop. 2006;97(3):247-51.

21. Wang CQ, Wu FW, Wang XR, Xu HB, Li E, Long GP, et al. Survey of an outbreak of trichinellosis in Lanchang county of Yunnan province. China Trop Med. 2013;13(11):1433-4.

22. Cui J, Wang ZQ, Wu F, Jin XX. An outbreak of paragonimiosis in Zhengzhou city. China Acta Trop. 1998;70(2):211-6.

23. Cui J, Li N, Wang ZQ, Jiang P, Lin XM. Serodiagnosis of experimentalsparganum infections of mice and human sparganosis by ELISA using ES antigensof Spirometra mansoni spargana. Parasitol Res. 2011;108:1551-6.

24. Long SR, Wang ZQ, Liu RD, Liu LN, Li LG, Jiang P, et al. Molecular identification of Trichinella spiralis nudix hydrolase and its induced protective immunity against trichinellosis in BALB/C mice. Parasit Vectors. 2014;7:600.

25. Zocevic AMP, Vallee I, Blaga R, Liu M, Lacour SA, Boireau P. Identification of Trichinella spiralis early antigens at the pre-adult and adult stages. Parasitology. 2011;138(4):463-71.

26. Wang SW, Wang ZQ, Cui J. Protein change of intestinal epithelial cells induced in vitro by Trichinella spiralis infective larvae. Parasitol Res. 2011;108(3):593-9.

27. Bradford MM. A rapid and sensitive method for the quantitation of microgram quantities of protein utilizing the principle of protein-dye binding. Anal Biochem. 1976;72:248-54.

28. Gamble HR, Bessonov AS, Cuperlovic K, Gajadhar AA, van Knapen F, Noeckler K, et al. International Commission on Trichinellosis: recommendations on methods for the control of Trichinella in domestic and wild animals intended for human consumption. Vet Parasitol. 2000;93(3-4):393-408.

29. Li F, Cui J, Wang ZQ, Jiang P. Sensitivity and optimization of artificial digestion in the inspection of meat for Trichinella spiralis. Foodborne Pathog Dis. 2010;7:879-85

30. Cui J, Liu RD, Wang L, Zhang X, Jiang P, Liu MY, et al. Proteomic analysis of surface proteins of Trichinella spiralis muscle larvae by two-dimensional gel electrophoresis and mass spectrometry. Parasit Vectors. 2013;6:355.

31. Yang W, Li LG, Liu RD, Sun GG, Liu CY, Zhang SB, et al. Molecular identification and characterization of Trichinella spiralis proteasome subunit beta type-7. Parasit Vectors. 2015;8:18.

32. Liu P, Cui J, Liu RD, Wang M, Jiang P, Liu LN, et al. Protective immunity against Trichinella spiralis infection induced by TsNd vaccine in mice. Parasit Vectors. 2015;8:185.

33. Wang ZQ LX, Zhang HW, Xu BL, Zhang X, Jiang P, Cui J. Serological survey for sparganum infection in people of central China. Helminthiologia. 2014;51(2):158-61.

34. Zhong ZR, Zhou HB, Li XY, Luo QL, Song XR, Wang W, et al. Serological proteome-oriented screening and application of antigens for the diagnosis of Schistosomiasis japonica. Acta Trop. 2010;116:1-8.

35. Zhang YW, Lee DL, Smith JE. Biochemical characterisation of Trichinella spiralis and T. pseudospiralis stichocyte antigens. Appl Parasitol. 1993;34(4):291-4.

36. Kapel CM, Gamble HR. Infectivity, persistence, and antibody response to domestic and sylvatic Trichinella spp. in experimentally infected pigs. Int J Parasitol. 2000;30(2):215-21.
37. Appleton JABR, Homan W, Van Knapen F. Consensus on Trichinella spiralis antigens and antibodies. Parasitol Today. 1991;7:190-2.

38. Bell RG, McGregor DD, Woan MC, Adams LS. Trichinella spiralis: selective intestinal immune deviation in the rat. Exp Parasitol. 1983;56(1):129-42.

39. Langelaar M, Aranzamendi C, Franssen F, Van Der Giessen J, Rutten V, van der Ley $P$, et al. Suppression of dendritic cell maturation by Trichinella spiralis excretory/secretory products. Parasite Immunol. 2009;31(10):641-5.

40. Zocevic A, Lacour SA, Mace P, Giovani B, Grasset-Chevillot A, Vallee I, et al. Primary characterization and assessment of a $T$. spiralis antigen for the detection of Trichinella infection in pigs. Vet Parasitol. 2014;205(3-4):558-67.

41. Capron A, Biguet J, Vernes A, Afchain D. Structure antigénique des helminthes: aspects immunologiques des relations hoste-parasite. Pathol Biol. 1968;16:121-38.

42. Mahannop P, Setasuban P, Morakote N, Tapchaisri P, Chaicumpa W. Immunodiagnosis of human trichinellosis and identification of specific antigen for Trichinella spiralis. Int J Parasitol. 1995;25(1):87-94.

43. Ren DF, Cui J, Wang ZQ, Han HM. Prokaryotic expression of the antigen gene Ts43 of Trichinella spiralis and identification of its recombinant protein. Chin J Zoonosis. 2008;24(6):539-42.

44. Wang R, Wang ZQ, Cui J. Immunodiagnostic value and immune protection of the recombinant Ts21 antigen of Trichinella spiralis. Chin J Parasitol Parasit Dis. 2009;27(1):17-21.

45. Frey CF, Schuppers ME, Nöckler K, Marinculić A, Pozio E, Kihm U, et al. Validation of a Western blot for the detection of anti-Trichinella spp. antibodies in domestic pigs. Parasitol Res. 2009;104(6):1269-77.

46. Gómez-Morales MA, Ludovisi A, Amati M, Cherchi S, Pezzotti P, Pozio E. Validation of an enzyme-linked immunosorbent assay for diagnosis of human trichinellosis. Clin Vaccine Immunol. 2008;15(11):1723-9.

47. Nöckler K, Reckinger S, Broglia A, Mayer-Scholl A, Bahn P. Evaluation of a Western blot and ELISA for the detection of anti-Trichinella-lgG in pig sera. Vet Parasitol. 2009;163(4):341-7.

48. Gómez-Morales MA, Ludovisi A, Amati M, Blaga R, Zivojinovic M, Ribicich M, et al. A distinctive Western blot pattern to recognize Trichinella infections in humans and pigs. Int J Parasitol. 2012;42(11):1017-23.

49. Vu Thi N, Pozio E, Van De N, Praet N, Pezzotti P, Gabriël S, et al. Anti-Trichinella IgG in ethnic minorities living in Trichinella-endemic areas in northwest Vietnam: study of the predictive value of selected clinical signs and symptoms for the diagnosis of trichinellosis. Acta Trop. 2014;139:93-8.

50. Conlan JV, Vongxay K, Khamlome B, Gomez-Morales MA, Pozio E, Blacksell SD, et al. Patterns and risks of Trichinella infection in humans and pigs in northern Laos. PLoS Negl Trop Dis. 2014;8(7):e3034.

51. Cui J, Wang ZQ, Zhang D. Study on specific diagnostic antigens in excretory-secretory products from muscle larvae of Trichinella spiralis. Chin J Parasitol Parasit Dis. 2003;21(5):268-71.

52. Aronstein WS, Lewis SA, Norden AP, Dalton JP, Strand M. Molecular identity of a major antigen of Schistosoma mansoni which cross-reacts with Trichinella spiralis and Fasciola hepatica. Parasitology. 1986;92(1):133-51.

53. Chan SW, Ko RC. Comparison between standard ELISA anddot-ELISA for serodiagnosis of human trichinosis. Trans R Soc Trop Med Hyg. 1988:82:892-4.

54. Roach TI, Wakelin D, Else KJ, Bundy DA. Antigenic cross-reactivity between the human whipworm, Trichuris trichiura, and the mouse trichuroids Trichuris muris and Trichinella spiralis. Parasite Immunol. 1988;10(3):279-91.

55. Zheng D, Wang ZQ, Cui J. Studies on common antigens among Trichinella spiralis, Paragonimus westermani and Clornorcis sinensis. J Trop Dis Parasitol. 2003;1(4):193-6.

56. Linder E, Thors C, Lundin L, Ljungstrom I, Farah S, Hagi H, et al. Schistosome antigen gp50 is responsible for serological cross-reactivity with Trichinella spiralis. J Parasitol. 1992;78(6):999-1005. 